\title{
Quality of care can increase while costs are reduced: essential actions for health services for older adults
}

\begin{abstract}
While demographic and epidemiological transitions have brought improvements in health and social indicators in Brazil, in comparison with previous decades, they have also resulted in other consequences, such as the expansion of the older population and greater fiscal pressure on public and private health systems. As this portion of the population grows, chronic diseases also increase, with a resulting increase in demand for health services, which, in turn, can generate scarcity and/or constraints on resources. The diseases that affect older adults are mostly chronic and multiple. Hospital admissions become more frequent and bed occupancy time is longer than in other age groups. This is the current challenge that this article aims to answer, offering a resolutive, more efficient and less costly healthcare model for the fastest growing age group in Brazil.
\end{abstract}

Volume 5 Issue 4 - 2020

\author{
Renato Veras \\ Full Professor at UERJ, Director at UnATI/UERJ, Doctor, PhD \\ from the University of London, Brazil
}

Correspondence: Renato Veras, Full Professor at UERJ, Director at UnATI/UERJ, Doctor, PhD from the University of London, Editor of the Brazilian Journal of Geriatrics and Gerontology (RBGG), Brazil, Email vera@uerj.br

Received: June 17,2020 | Published: July 08, 2020

\section{Introduction}

The world has changed since the Covid-19 pandemic, especially for older adults. In this global health crisis, we have learnt the importance of knowledge, science and new strategies to deal with an unknown disease. ${ }^{1}$ The importance of health care, promotion and prevention has become clear. The present article sets out the fundamental requirements for the implementation of a care model based on lines of care, that is, on the strategies for establishing a care pathway, with the aim of organizing the flux of individuals according to their needs, with greater effectiveness and efficiency. ${ }^{2}$

\section{The essentials}

One of humanity's greatest achievements has been the extension of life expectancy. As a consequence, there is greater fiscal pressure on health systems all over the world, as the probability of multiple chronic diseases, which are often long-term, increases, generating greater costs. ${ }^{3}$

As the model of care adopted in many countries, including Brazil, is based on large numbers of specialist doctors, care becomes fragmented, with no single doctor directly responsible for the patient (Ref. . There is an excess of consultations, medications and exams, hospital admissions become more frequent and the bed occupancy time for older adults is longer than with other age groups. ${ }^{4}$

\section{Detailing the model}

There are certain essential items for creating a suitable care model for the older age group: one which makes a difference from a medicalclinical point of view; which provides care beyond the realm of the disease; which considers the frailties of older clients; which invests in information, innovation and cutting-edge technology and which establishes trust and loyalty with the health team (made up of welltrained and highly-qualified professionals, remunerated based on their performance). In short, high quality care, offering what is needed in an efficient manner and at a lower cost.

\section{The structure of the model}

What we suggest is a change to the logic of multiple doctors who are responsible for the same client. The theoretical care model proposed is based around two important segments, which we call "low complexity instances" and "high complexity instances". These are two major, complementary healthcare segments, with very different characteristics.

In our proposal, the emphasis of the model is on low complexity instances, with a focus on health promotion, prevention and the coordination of care. We know that integrated models seek to solve the problem of fragmented and poorly coordinated care in current health systems. There are five levels of segmented care, three of which are considered low complexity: Level 1 is intake; Level 2 involves the integrated care unit;and Level 3 is the geriatric outpatient clinic.

The high complexity levels, meanwhile, are Level 4, which covers short-term actions such as emergency care, the hospital, the day hospital and palliative care, and Level 5, which comprises long-term actions such as rehabilitation units, care homes and long-term care facilities for older adults.

The goal is to maintainover $90 \%$ of older adults in low complexity instances of care. ${ }^{5}$ In these the older adults are accompanied by their doctor (the traditional family doctor) or a physician corresponding to the general practitioner (GP) of the English model. These structures aim to closely monitor the client, keeping their illnesses under control. ${ }^{6}$ It is not a question of preventing progression to the higher complexity instances, but of understanding that the use of the hospital should be an exception, and employed for as short a time as possible. ${ }^{7}$

One of the criticisms of the model proposed here is the value given to social, behavioral and spiritual situations, among others, which are not part of the narrow world of the disease. There are criticisms, too, of the fact that in the field of collective health, denominations are adopted which are unusual in medical practice. I consider such criticisms inconsistent. It is a mistake to exclusively consider the disease itself as the field of action, excluding the issues involved in care for the restoration of health. ${ }^{8}$

Monitoring the health conditions of a given population, as well as the associated factors, is a key tool for guiding prevention strategies, which should aim to: favorably intervene in the natural history of the disease; anticipate the emergence of complications; prevent the exacerbations and complications of chronic diseases; increase patient 
involvement in self-care and build a database of chronic patients, or in other words the majority of older adults. ${ }^{9}$

The current care models stem from an era when Brazil was a country of young people and acute illnesses, based on which, even today, most health care and services remain structured. Our model calls for a partnership formed by a geriatric doctor and a gerontological nurse to be responsible for a portfolio of around 600 clients. There would be working weeks of 20 hours for the doctor and 25 hours for the nurse. The doctor will be responsible for clinical management while the nurse is the care manager, offering support to the doctor, the client and their family, consolidating the referral role during intake, and strengthening bonds. ${ }^{10}$

In addition to the geriatrician and the nurse, the team is composed of a physiotherapist, psychologist, social worker, speech therapist, nutritionist and workshop staff (professionals who perform dynamic integrative activities in the community center linked to the program). This center is a place for the integration of various educational, promotion and prevention actions. These include health workshops, therapy groups, yoga, ballroom dancing, cognitive stimulation, psychology groups, nutrition, singing, postural instruction, pelvic and muscle strengthening, all conducted by professionals from the multidisciplinary team who contribute the specific tools of their area of knowledge and performance. The intention of establishing a community center within a health center is to reduce the problem of loneliness for older adults, improve their social contact and allow them to develop new skills at an older age, as it is a stimulating space for exchanging experiences, mediated by a pedagogical approach. ${ }^{11}$

Whenever the care needs of users require other levels of care, referral is carried out, but always by the client's doctor (geriatrician, general practitioner or family doctor). We recommend, however, five areas of medical specialties related to the model, which work to assist general practitioners, selected based on demand and prevalence. These are areas in which annual preventive control tests are carried out, namely: cardiology, gynecology, uro-proctology, dermatology and ophthalmology. Appointments with the listed specialties will only be possible at the request of the patient's general practitioner. ${ }^{12}$

The relationship between doctor, care manager (nurse) and patient must be close. The better the health professional knows their patient's history, the better the results. Frequent contact with clients is essential to establish trust and generate loyalty to the model. This is why technical quality and qualified care are fundamental. The training and knowledge of healthcare professionals involved in this model must be continually kept up to date, to ensure they are as qualified as possible.

\section{Remuneration}

As a high level of technical and behavioral requirements are required from health professionals, it is therefore recommended that remuneration is also high. Performance based pay, for example, establishes bonus levels as high as $30 \%$. Every three months, an assessment of the professional's performance is made based on predetermined indicators. The prerequisites of the award are attendance and punctuality, which are fundamental for guaranteeing the number of consultations, a factor in ensuring the quality of the service. There is a further requirement for the bonus scoring system: the proper recording of information in the electronic medical records of the participants, as well as their eventual referrals, either to specialist doctors or for hospitalization. ${ }^{13}$ Another topic is the resolutive capacity of the geriatrician. According to international studies, general practitioners can resolve $85 \%$ to $95 \%$ of clinical situations. Referrals to clinical specialties - whichrepresent the biggest cost factor - shouldbe an exception. The loss ratio is the main economic and financial indicator established for the evaluation of the program, which is why this item is given greater weight, with doctors gaining up to two points in the evaluation of their performance. ${ }^{14}$

\section{Innovation and technology}

Technology must be a differentiating factor. We propose the use of a comprehensive, flexible and high quality information system. Its use begins with the registration of the beneficiary. From this moment on, the entire care path will be monitored at every level, verifying the effectiveness of actions and contributing to decision making and monitoring. A wide-ranging, high-quality information system can document not only the clinical evolution of the older adult, but also their participation in individual or collective prevention actions, as well as the support of the nurse and the phone calls made, which must be resolutive, carried out by trained and qualified personnel. Telephone contact between patients and professionals should be carried out with the full sharing of information with the team, for the benefit of a comprehensive assessment of the patient. This differs from existing medical records in that it includes a register of the patient's life history and their health events. ${ }^{15}$ Another efficient differentiating factor is the availability of a mobile phone app with individualized information and reminders of appointments and prescribed actions. The app may, among other actions, request that the client takes a photo of their breakfast and sends it to the nutritionist, who will observe if the meal is balanced, or if it contains adequate quantities of fiber and other constituents.

The system includes other actions that seek to increase the resolutive capacity of care. One is the second medical opinion, in which professionals of the highest standard can share their knowledge with the general practitioner when necessary.

We know that after the pandemic, the use of technology for consultations, the resolution of queries and other activities will increase. We also expect a huge increase in telemedicine, providing greater contact between doctor and nurse and their patients. This action will not mean the end of the face-to-face appointment, but will allow for a greater number of consultations and better monitoring, with significant cost savings.

\section{Conclusion}

In Rio de Janeiro, a traditional health care provider ${ }^{16}$ has been employing this model for five years. The results have been excellent. If older clients used to have a negative financial impact on the company, today the loss ratio for this group is continually improving. In the first year of operation the ratio was $108.2 \%$, while today, five years later, with a reduction every year, it is $56.6 \%$, representing a successful case study and an example to be followed.

We believe that it is possible to grow old in a healthy manner, with a good quality of life, as long as all actors in the sector consider themselves responsible for improving care and allow themselves to innovate. ${ }^{17}$ Sometimes this simply means salvaging care and values that have been lost. It is exactly this that can make a difference in our health system. ${ }^{18,19}$

\section{Acknowledgments}

None. 


\section{Conflicts of interest}

The authors declare have no conflict of interest about the publication of this paper.

\section{References}

1. Veras RP. A contemporary care model for older adults should seek coordinated care, grater quality and the reduction of costs. International Journalof Family \& Community Medicine. 2019;3(5):210-214.

2. Veras R, Oliveira Ma. Aging in Brazil: the construction of a care model. Ciênc saúde coletiva. 2018;23(6):1929-1936.

3. Veras R. (2019) An innovative health care model for the elderly in brazil: care coordination extends care quality and reduces costs. Int J Intern Med Geriatr. 2019;1(2):33-42.

4. Oliveira M, Veras R, Cordeiro H. The importance of the gateway in the system: the integral model of care for the elderly. Physis (Rio J.). 2018;28(4):e280411.

5. Veras RP. Caring Senior: um modelo brasileiro de saúde com ênfase nas instâncias leves de cuidado. Rev Bras Geriatr Gerontol. 2018;21(3):1-7.

6. Veras RP. An innovative healthcare model for the elderly in brazil: care coordination extends care quality and reduces costs. Int J Intern Med Geriatr. 2019;1(2):33-42.

7. Veras R. Why are our words so different from our actions?. Rev bras geriatr gerontol. 2018;21(4):387-388.

8. de Lima KC, Veras RP, Caldas CP, et al. Effectiveness of intervention programs in primary care for the robust elderly. Salud Pública México. 2015;57(3):265-274.
9. Veras R. A contemporary and innovative care model for older adults. Rev Bras Geriatr Gerontol. 2020;23(1).

10. Veras RP. A contemporary care model for older adults should seek coordinated care, grater quality and the reduction of costs. Int J Fam Community Med. 2019;3:210-214.

11. Lima KC, Caldas CP, Veras RP, et al. Health promotion and education:a study of the effectiveness of programs focusing on the aging process. Int J Health Serv. 2017;47(3):550-570.

12. Veras RP. Coordination of care: a contemporary care model for the older age group. MOJ Gerontol Geriatr. 2020;5(2):50-53.

13. Oliveira M, Cordeiro H, Veras RP. The remuneration model defining the way of caring: why reward inefficiency in caring for the elderly?. Jornal Brasileiro De Economia Da Saúde. 2018;10:198-202.

14. Médice AC, Abicalaffe C, Tavares L. Pagamento por performance em saúde, Book. Edition: First (on line). February 2015.

15. Veras R. New model of healthcare improve quality andreduce costs. MOJ Gerontol Ger. 2019;4(4):119-122.

16. Veras RP, Gomes JAC, Macedo ST. Coordination of care increases the quality of care and reduces costs. Rev Bras Geriatr Gerontol. 22(2):2009.

17. Veras RP. New model of health care improves quality and reduce costs. MOJ Gerontol. Geriatr. 2019;4(4):119-122.

18. Veras R. Coordinationofcare: a contemporary care model for theolder age group. MOJ Gerontol Ger. 2020;5(2):50-53.

19. Kalache A, Alexandre S, Karla CG, et al. Aging and inequalities: social protection policies for older adults resulting from the Covid-19 pandemic in Brazil. Rev bras geriatr gerontol. 2020;23(6). 